\title{
Bilayer Interdiffused Heterojunction Organic Photodiodes Fabricated by Double Transfer Stamping
}

\author{
Hyunsoo Kim, Byeongseop Song, Kyusang Lee, Stephen Forrest, and Jerzy Kanicki*
}

\begin{abstract}
Photodetectors based on organic materials have attracted attention due to their wide spectral response, ${ }^{[1-3]}$ low dark current density, ${ }^{[4,5]}$ high photoresponse, ${ }^{[6,7]}$ and fast response time. ${ }^{[8]}$ In particular, bulk heterojunctions (BHJs) have been exploited in organic photodetectors (OPDs) due to their high photocarrier generation efficiency and simplified solutionbased fabrication. ${ }^{[9,10]}$ However, the coexistence of the donor and acceptor materials at the cathode and anode interfaces can lead to high dark currents due to formation of low barrier heights for carrier injection, leading to shunt currents. ${ }^{[10]}$ Dark current suppression can be achieved, in principle, by controlling donor/acceptor (D/A) segregation using a double active layer structure. ${ }^{[4,11]}$ To fabricate the bilayer using a solution process, "orthogonal" solvents are required for each material to avoid resolvation of an already-deposited layer. ${ }^{[12]}$ Ayzner et al. reported that o-dichlorobenzene and dichloromethane (DCM) are orthogonal solvents useful in the sequential deposition of poly(3-hexylthiophene) (P3HT) and [6,6]-phenyl C61-butyric acid methyl ester (PCBM) layer. ${ }^{[13]}$ This approach nevertheless allows partial mixing of the materials due to swelling of the P3HT by DCM used in depositing the PCBM. ${ }^{[14-17]}$ This induces micropenetration of each material to the counter-electrodes, forming current pathways resulting in shunt currents. An alternative is to use a silicon wafer treated with a releasing agent as a stamp to transfer one layer from the silicon wafer on top of another layer located on the target substrate, but this can result in surface contamination. ${ }^{[18,19]}$ To minimize these adverse effects, the lamination process to the target substrate using a polydimethylsiloxane (PDMS) stamp treated in an $\mathrm{O}_{2}$ plasma enables the spincasting of a polymer film directly onto the PDMS stamp. ${ }^{[20]}$
\end{abstract}

H. Kim, B. Song, S. Forrest, J. Kanicki

Department of Electrical Engineering and

Computer Science

University of Michigan

Ann Arbor, MI 48109, USA

E-mail: kanicki@umich.edu

K. Lee

Department of Electrical and Computer Engineering

University of Virginia

Charlottesville, VA 22904, USA

K. Lee

Department of Materials Science and Engineering

University of Virginia

Charlottesville, VA 22904, USA

S. Forrest

Department of Physics

University of Michigan

Ann Arbor, MI 48109, USA

DOI: 10.1002/adom.201600784
However, $\mathrm{O}_{2}$ plasma treatment results in an increase of stamp surface adhesive energy, preventing efficient layer transfer from the PDMS to the substrate.

To address these problems, we introduce double transfer stamping (DTS) to promote interdiffusion between donor and acceptor layers to form well-defined interdiffused bilayer heterojunction (BiHJ) OPDs sandwiched between donor and acceptor layers that are in direct contact with their respective metal electrodes. The thermal annealing step is used to enable interdiffusion between the donor and acceptor layers, forming the active layer. Using this approach, we demonstrate an inverted interdiffused P3HT/PCBM bilayer photodiode whose dark current density is $7.7 \pm 0.3 \mathrm{nA} \mathrm{cm}-2$ with an external quantum efficiency of $60 \% \pm 1 \%$ and a peak specific detectivity of $(4.8 \pm 0.2) \times 10^{12} \mathrm{~cm} \mathrm{~Hz}^{1 / 2} \mathrm{~W}^{-1}$.

In Figure 1, we show the energy level diagram for the OPD to illustrate how donor and acceptor bilayer interdiffusion can effectively suppress the dark current under reverse bias while maintaining a high quantum efficiency; the energy values shown are found elsewhere. ${ }^{21]}$ Although other approaches have been demonstrated to suppress dark current injection such as addition of a hole blocking layer (e.g., $\mathrm{ZnO})^{[21,22]}$ at the anode, or an electron blocking layer (e.g., poly[ $N, N^{\prime}$-bis(4butylphenyl)- $N, N^{\prime}$-bis(phenyl)-benzidine]) at the cathode, ${ }^{[2]}$ the success of these methods are fabrication process dependent since the additional layers can introduce interface states that adversely affect device performance. ${ }^{[23-25]}$ A simple and reliable means to suppress the reverse-biased dark current, therefore, is to have only the acceptor material in contact with the cathode, while only donor material contacts the anode. ${ }^{[4,10]}$ In the inverted $\mathrm{BHJ}$ in Figure 1a, the hole injection barrier at the cathode is $\Delta E_{\text {hole }}=1.4 \mathrm{eV}$ (equal to the difference between the highest occupied molecular orbital (HOMO) energy of P3HT at $5.0 \mathrm{eV}^{[26]}$ and $\left.\Phi_{\mathrm{ITO} / \mathrm{PEIE}}=3.6 \mathrm{eV}^{[27]}\right)$, and the electron injection barrier at the anode is $\Delta E_{\text {electron }}=2.6 \mathrm{eV}$ (equal to the difference between $\Phi_{\mathrm{MoO} 3} 6.9 \mathrm{eV}^{[28]}$ and the lowest unoccupied MO (LUMO) energy of PCBM of $4.3 \mathrm{eV}^{[26]}$ ). A significant increase of the barrier height is obtained by the formation of the bilayer $\mathrm{HJ}$ in Figure $1 \mathrm{~b}$. Then, the hole injection barrier at the cathode/PCBM interface is $\Delta E_{\text {hole }}=2.5 \mathrm{eV}$ (equal to the difference between the HOMO energy of PCBM of $6.1 \mathrm{eV}^{[26]}$ and $\Phi_{\text {ITO/PEIE }}$ and the electron injection barrier at the anode/P3HT layer is $\Delta E_{\text {electron }}=3.9 \mathrm{eV}$ (equal to the difference between $\Phi_{\mathrm{MoO} 3}{ }^{[28]}$ and the LUMO energy of P3HT of $3.0 \mathrm{eV}^{[26]}$. We expect that the increased $\Delta E_{\text {hole }}$ and $\Delta E_{\text {electron }}$ at cathode/anode interfaces reduce the dark leakage current, while the lower energetic barrier (e.g., $\Delta E_{\text {hole }}$ ) encourages current injection. The device structure is shown in Figure 1c. The structure maximizes the area of the D/A interfaces within a given volume via thermal interdiffusion, while maintaining undiluted electron 


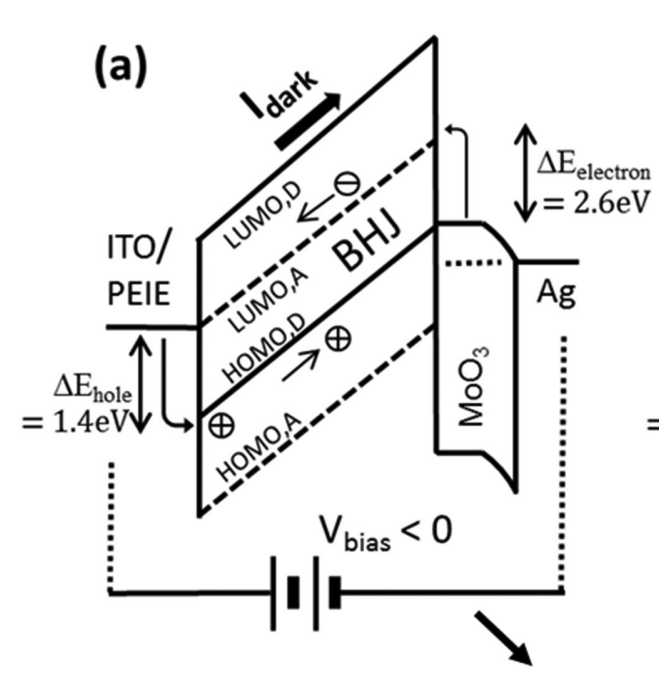

www.advancedsciencenews.com

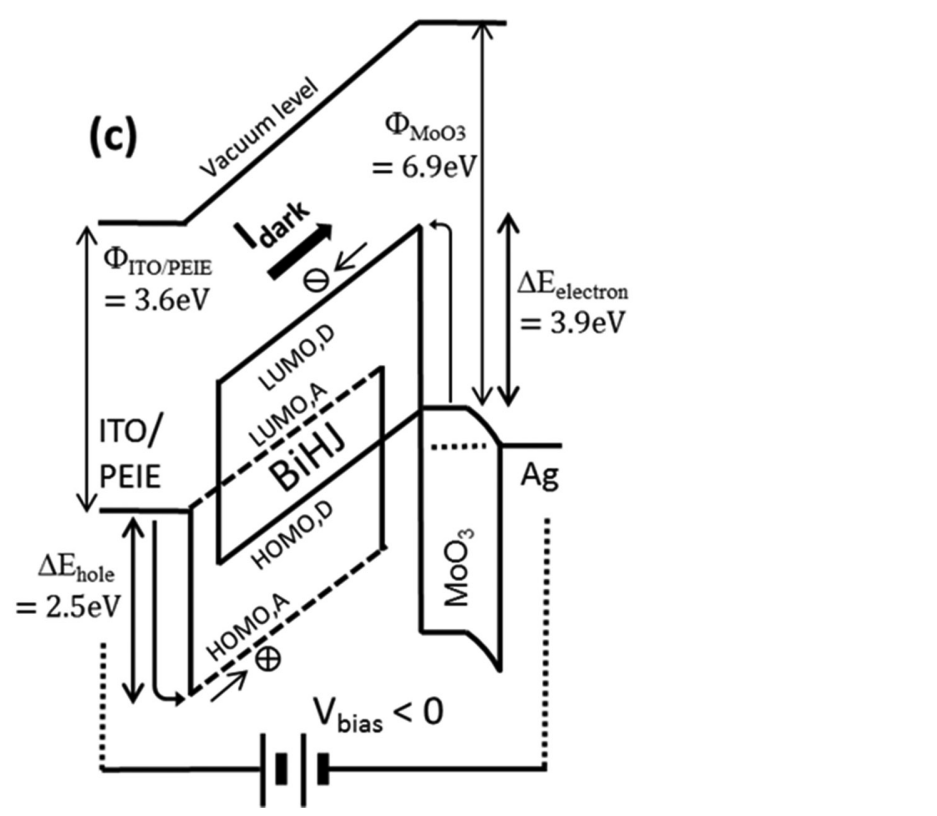

Figure 1. Schematic energy diagrams of the a) conventional bulk heterojunction (BHJ) OPD, b) bilayer OPD, and c) bilayer interdiffused heterojunction $(\mathrm{BiHJ})$ OPD under reverse bias. The arrows show the carrier injection direction at each electrode. LUMO,D and HOMO,D indicate LUMO and HOMO level of electron donor ( $\mathrm{P} 3 \mathrm{HT}$ ) while LUMO,A and $\mathrm{HOMO}, \mathrm{A}$ corresponds to electron acceptor (PCBM).

donor and acceptor layer at the anode and cathode electrode, respectively.

Figure 2 illustrates the DTS fabrication process. Indium tin oxide (ITO) coated glass substrates were sequentially precleaned by rinsing in acetone, isopropyl alcohol, and deionized water by sonication for $5 \mathrm{~min}$, and then exposed to an oxygen plasma for $5 \mathrm{~min}$. The low work function cathode was prepared by spincoating polyethylenimine ethoxylated (PEIE) solution on the ITO coated glass ${ }^{[27]}$ at $2000 \mathrm{rpm}$ for $60 \mathrm{~s}$, followed by thermal annealing at $100{ }^{\circ} \mathrm{C}$ for $10 \mathrm{~min}$ in air. This resulted in a $<10 \mathrm{~nm}$ thick PEIE layer. The substrates were transferred into a glove box filled with $\mathrm{N}_{2}$ gas $\left(\mathrm{O}_{2}, \mathrm{H}_{2} \mathrm{O}\right.$ level $\left.<0.5 \mathrm{ppm}\right)$ for deposition of the photoactive layers. The PCBM in chlorobenzene (CB) solution was spin-coated for $60 \mathrm{~s}$ to form $90 \pm 5 \mathrm{~nm}$ thick electron acceptor layer on the PEIE/ITO substrate. To fabricate the
PDMS stamp having suitable surface energy for the DTS process, contact angles were measured by dropping $\mathrm{P} 3 \mathrm{HT}$ in $\mathrm{CB}$ solution on PDMS surfaces with varying elastomer-to-curing agent $(\mathrm{E} / \mathrm{C})$ ratios. The surface contact angles measured using a goniometer in air shown in Figure S1 (Supporting Information) decrease from $33^{\circ} \pm 3^{\circ}$ to $18^{\circ} \pm 1^{\circ}$ when the elastomer in PDMS ratio increases from 5:1 to 20:1, suggesting a decrease in PDMS surface hydrophobicity for increased $\mathrm{E} / \mathrm{C}$ ratios. As the content of the cross-linker is reduced, the PDMS modulus of elasticity becomes too small to achieve the desired stiffness. We therefore employed PDMS stamps with 15:1 and 5:1 ratios of Sylgard elastomer and curing agent to achieve the optimal surface energy.

The P3HT solution was drop-cast in the glove box on a 5:1 PDMS stamp followed by combining with a 15:1 PDMS stamp 
(a)

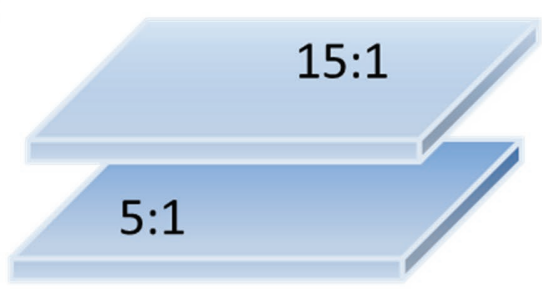

(b)
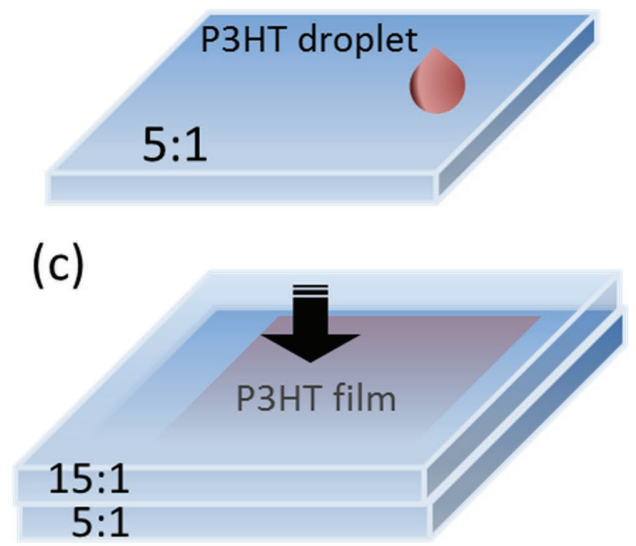

(d)

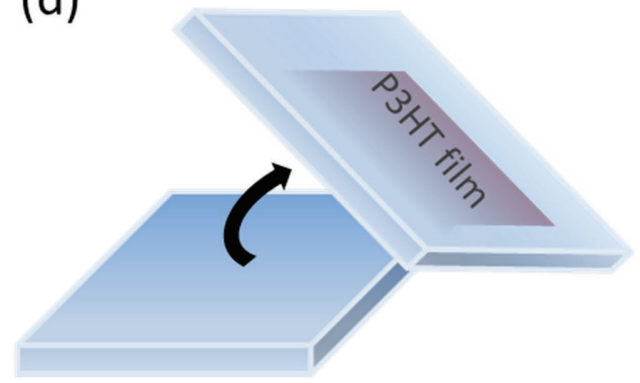

(e)

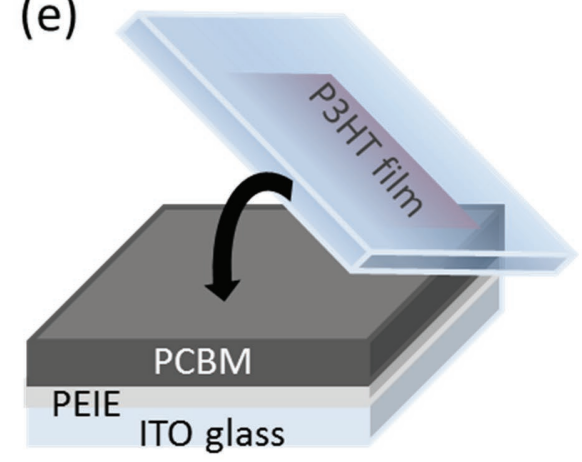

(f)

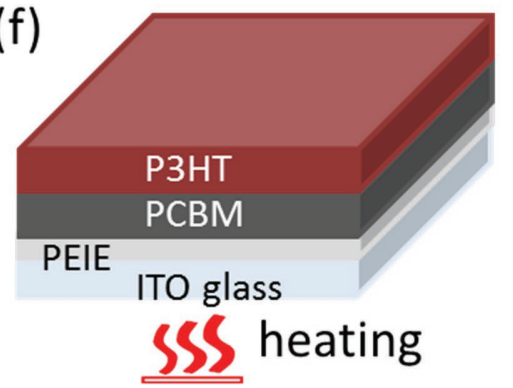

(g)

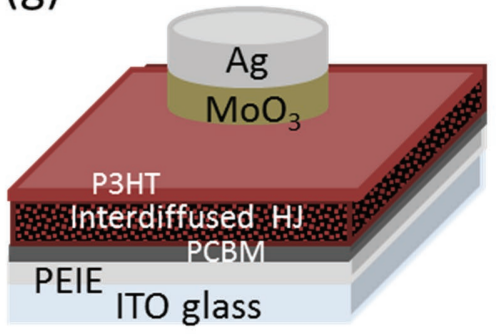

Figure 2. Schematic illustration of proposed double transfer stamping (DTS) process for fabricating bilayer heterojunction organic photodiodes: a) Prepare PDMS stamps with different surface energies. b) Drop-cast P3HT droplet on the PDMS stamp (5:1) with the lowest surface energy. c) Squeeze the drop-casted solution with the high surface energy PDMS stamp (15:1) to form a uniform film. d) Detach PDMS stamp, transferring the film to the 15:1 stamp. e) Transfer the P3HT film from the stamp onto a PCBM/PEIE/ITO substrate. f) Heat substrate to allow interdiffusion of PCBM into P3HT. g) Complete the device fabrication by depositing $\mathrm{MoO}_{3} / \mathrm{Ag}$ anode. All the processes are done inside a $\mathrm{N}_{2}$-filled glove box to prevent degradation.

to form a uniform polymer film between the two stamps by applying pressure. After room temperature solvent evaporation for about $10 \mathrm{~s}$ into the permeable stamp, the 15:1 PDMS stamp was detached. During this step, the P3HT polymer film is transferred from 5:1 to $15: 1$ stamp having a higher adhesion. The thickness of the printed polymer film measured by surface profilometry is $90 \pm 5 \mathrm{~nm}$. Next, the polymer film formed on the 15:1 PDMS stamp was pressed onto the PCBM/PEIE/ITO to form a $190 \pm 10 \mathrm{~nm}$ thick P3HT/PCBM bilayer. Following transfer, the bilayer is thermally annealed for $5 \mathrm{~min}$ at $70-150^{\circ} \mathrm{C}$, allowing the PCBM to diffuse into the P3HT film. ${ }^{[29]}$ Finally, the devices were transferred into a thermal evaporator for deposition of a $15 \mathrm{~nm} \mathrm{MoO}_{3} / 100 \mathrm{~nm} \mathrm{Ag}$ anode on the top of P3HT through an array of $1 \mathrm{~mm}$ diameter circular holes in shadow mask.
The ultraviolet-visible (UV-vis) absorption spectra were measured for $200 \mathrm{~nm}$ thick as-cast and $110^{\circ} \mathrm{C} \mathrm{BiHJ} \mathrm{films,} \mathrm{as}$ shown Figure 3a. The absorption coefficients $(\alpha)$ of the as-cast, $110{ }^{\circ} \mathrm{C} \mathrm{BiHJ}$ along with neat P3HT and PCBM films are plotted in Figure $3 \mathrm{~b}$ versus photon energy. The broad absorption spectra of the as-cast and $110^{\circ} \mathrm{C} \mathrm{BiHJ} \mathrm{film} \mathrm{are} \mathrm{simply} \mathrm{the}$ superposition of the absorption of the P3HT and PCBM films. The $110^{\circ} \mathrm{C}$ annealed $\mathrm{BiHJ}$ film showed a slight decrease of the P3HT absorption peak, while PCBM absorption peak increased by $10 \%$ compared to the as-cast $\mathrm{BiHJ}$ film. Overall, the spectra were similar over the entire wavelength region, with slight blueshift of as-cast film relative to $110^{\circ} \mathrm{C}$ film around $550-650 \mathrm{~nm}$. The $\pi-\pi^{*}$ transition absorption peak for P3HT is observed from 450 to $550 \mathrm{~nm}^{[30]}$ and the peak for PCBM at $345 \mathrm{~nm}^{[31]}$ The optical energy gaps $\left(E_{\mathrm{G}}\right)$ of as-cast and $110{ }^{\circ} \mathrm{C}$ annealed $\mathrm{BiHJ}$ 

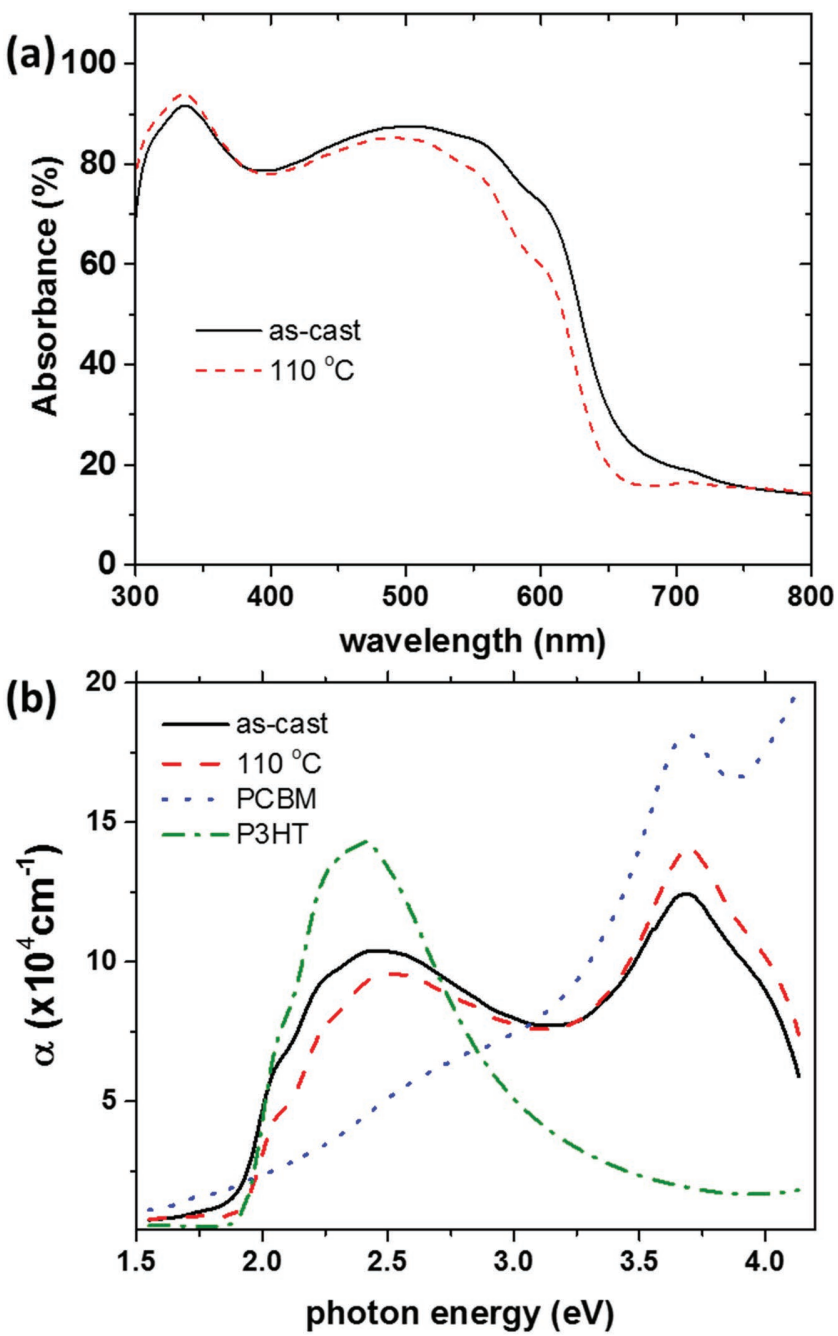

Figure 3. a) Absorbance spectra of as-cast and $110^{\circ} \mathrm{C} \mathrm{BiHJ} \mathrm{active} \mathrm{layer.}$ The thicknesses of the films are $200 \mathrm{~nm}$. b) Absorption coefficient plot versus photon energy for as-cast, $110^{\circ} \mathrm{C}, \mathrm{PCBM}$, and $\mathrm{P} 3 \mathrm{HT}$ films deposited on glass substrates.

film, estimated from the long wavelength absorption edges were about $1.90 \pm 0.01 \mathrm{eV}^{[32]}$

The dark current density $\left(J_{\mathrm{d}}\right)$ versus applied voltage $(V)$ characteristics changes with the thermal annealing conditions for the fabricated BiHJ OPDs as shown in Figure 4. The characteristics are fit (solid lines) with the modified diode equation for organic heterojunctions ${ }^{[33]}$

$J_{\mathrm{d}}(V)=J_{\circ}\left[\exp \left(\frac{q\left(V-J_{\mathrm{d}}(V) R_{\mathrm{S}} A\right)}{n k T}\right)-1\right]+\frac{V-J_{\mathrm{d}}(V) R_{\mathrm{S}} A}{R_{\mathrm{sh}}}$

Here, $J_{\mathrm{o}}$ is the dark saturation current density, $A$ is the device area, $n$ is the ideality factor, $k$ is Boltzmann's constant, $T$ is the temperature, $R_{\mathrm{S}}$ is the series resistance, and $R_{\mathrm{Sh}}$ is the shunt resistance. All parameters are extracted from the fitted dark current plots for $\mathrm{T}=299 \mathrm{~K}$ and summarized in Table 1 .

Higher dark currents observed for the as-cast device are due to residual solvent that can potentially introduce doping or traps, resulting in increased polaron pair recombination under reverse bias. ${ }^{[34,35]}$ We observe that $J_{\mathrm{d}}$ at $-1.5 \mathrm{~V}$ decreases by more than one order of magnitude when the annealing temperature is increased to $110{ }^{\circ} \mathrm{C}$. Annealing therefore leads to solvent evaporation from the film and interdiffused layer formation. When the annealing temperature is $150{ }^{\circ} \mathrm{C}$, we observe a sharp increase in $J_{\mathrm{d}}$ due to enhanced PCBM interdiffusion into P3HT, eventually penetrating to the counterelectrode (anode) and forming shunt current pathways. ${ }^{[29]}$ This significantly reduces the carrier injection barrier (e.g., $\Delta E_{\text {electron}}$ ) at the cathode, leading to the observed increase in dark current at high reverse bias.

The capacitance-voltage $(C-V)$ characteristics of the as-cast and $110{ }^{\circ} \mathrm{C}$ annealed $\mathrm{BiHJ}$ OPDs are shown in Figure 5. At high reverse bias, the capacitance for both devices saturates due to complete depletion of the organic layers, ${ }^{[36]}$ leading to a geometric capacitance, $C_{A}=\varepsilon \varepsilon_{0} \mathrm{~A} / t$, where the $\varepsilon$ is the dielectric constant of active layer, $\varepsilon_{0}$ is the vacuum permittivity, and $t$ is the layer thickness. The capacitances for the as-cast and $110{ }^{\circ} \mathrm{C}$ devices at $-2 \mathrm{~V}$ bias are $C_{\text {as-cast }}=153 \mathrm{pF}$ and $C_{110}{ }^{\circ} \mathrm{C}=123 \mathrm{pF}$, respectively (Figure 5 , inset). When the solvent is removed, the active layer thickness decreases by $\approx 5 \%$ (e.g., $190 \pm 5$ to $180 \pm 5 \mathrm{~nm}$ ). This should lead to $C_{110}{ }^{\circ} \mathrm{C}>C_{\text {as-cast }}$, which is opposite to observation. We attribute this to the change of layer morphology leading to a concomitant change in the dielectric constant. Assuming that $C_{\text {as-cast }}$ is composed of two series-connected capacitors of P3HT and PCBM films of the same thickness, we can obtain

$C_{\text {as-cast }}=\frac{C_{\mathrm{P} 3 \mathrm{HT}} C_{\mathrm{PCBM}}}{C_{\mathrm{P} 3 \mathrm{HT}}+C_{\mathrm{PCBM}}}=\varepsilon_{0} \frac{A}{t / 2} \frac{\varepsilon_{\mathrm{P} 3 \mathrm{HT}} \varepsilon_{\mathrm{PCBM}}}{\varepsilon_{\mathrm{P} 3 \mathrm{HT}}+\varepsilon_{\mathrm{PCBM}}}$

where $\varepsilon_{\mathrm{P} 3 \mathrm{HT}}=4.4^{[37]}$ and $\varepsilon_{\mathrm{PCBM}}=3.9^{[38]}$ are the dielectric constants of P3HT and PCBM films, respectively. The calculated $C_{\text {as-cast }}=151 \mathrm{pF}$ matches the experimental value, while the capacitance of the $110{ }^{\circ} \mathrm{C}$ annealed device can be approximated to $C_{110}{ }^{\circ} \mathrm{C}=C_{\mathrm{BiHJ}}$ due to the intermixed layer formed by annealing. Thus, the capacitance can be simplified as

$C_{1100^{\circ} \mathrm{C}} \approx C_{\mathrm{BiHJ}}=\varepsilon_{\mathrm{BHH}} \varepsilon_{0} \frac{A}{t}$

where $\varepsilon_{\mathrm{BiHJ}}$ is the dielectric constant of the mixed P3HT:PCBM $\mathrm{BiHJ}$ film. The calculated $\varepsilon_{\mathrm{BiHJ}}$ based on the measured $C_{110}{ }^{\circ} \mathrm{C}$ and thickness is 3.2 , which is comparable to $\varepsilon_{\mathrm{BiHJ}}=3.3$ reported previously. ${ }^{[36]}$ The smaller $\varepsilon_{\mathrm{BiHJ}}$ of the mixed layer compared to $\varepsilon_{\text {РзНT }}$ and $\varepsilon_{\text {PCBM }}$ is possibly due to the solvent removal (the dielectric constant of $\mathrm{CB}$ is $5.62^{[39]}$ ) by thermal annealing.

Table 1. The fit parameters for the BiHJ OPDs with different annealing conditions.

\begin{tabular}{lccccc}
\hline $\begin{array}{l}\text { Annealing } \\
\text { conditions }\end{array}$ & $\begin{array}{c}J_{\mathrm{d}} \\
{\left[\mathrm{A} \mathrm{cm}^{-2}\right] @-1.5 \mathrm{~V}}\end{array}$ & $\begin{array}{c}R_{\mathrm{sh}} \mathrm{A} \\
{\left[\Omega \mathrm{cm}^{2}\right]}\end{array}$ & $\begin{array}{c}R_{\mathrm{s}} \mathrm{A} \\
{\left[\Omega \mathrm{cm}^{2}\right]}\end{array}$ & $n$ & $\begin{array}{c}J_{\circ} \\
{\left[\mathrm{A} \mathrm{cm}^{-2}\right]}\end{array}$ \\
\hline As-cast & $9.38 \times 10^{-8}$ & $1.5 \times 10^{7}$ & 55 & 1.3 & $3.0 \times 10^{-9}$ \\
$70^{\circ} \mathrm{C}$ & $3.32 \times 10^{-8}$ & $4.0 \times 10^{7}$ & 50 & 1.45 & $1.5 \times 10^{-9}$ \\
$110^{\circ} \mathrm{C}$ & $7.72 \times 10^{-9}$ & $1.8 \times 10^{8}$ & 12 & 1.5 & $3.0 \times 10^{-10}$ \\
\hline
\end{tabular}




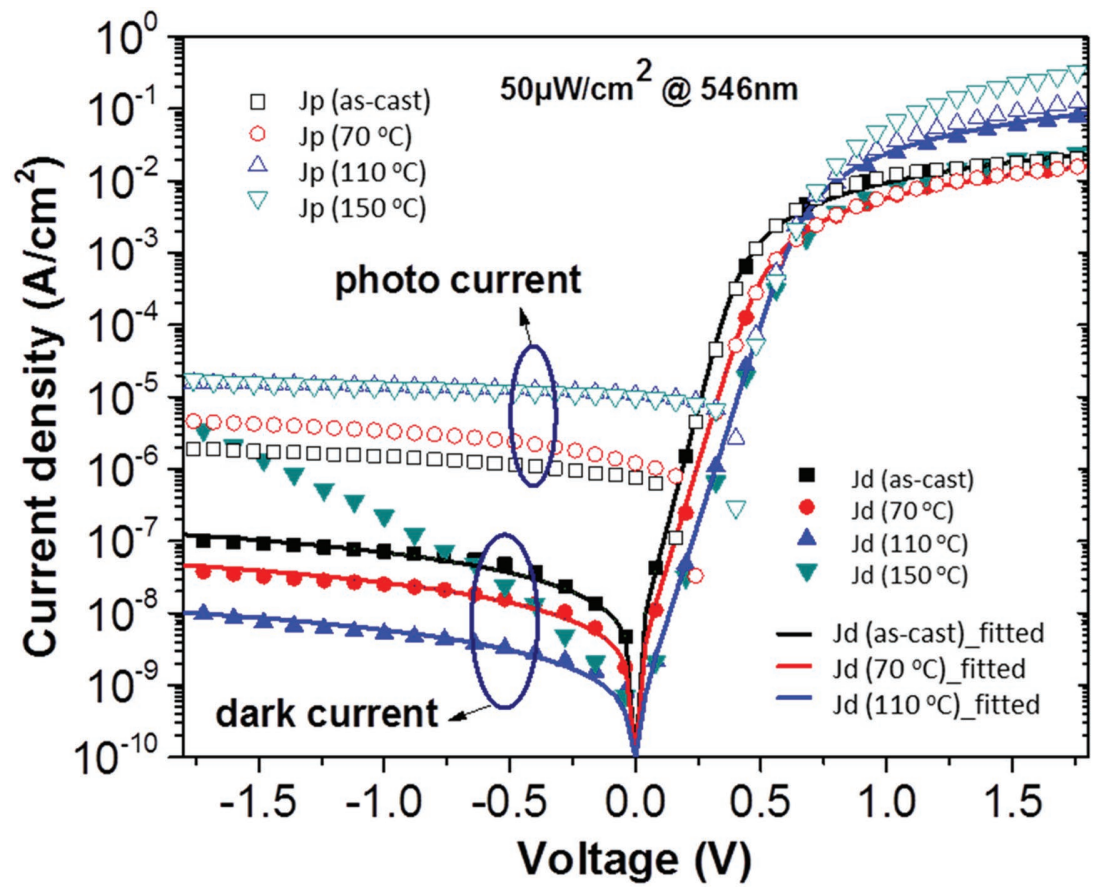

Figure 4. Dark (filled symbols) and illuminated (open symbols) current density (U) versus voltage $(V)$ characteristics for OPDs with different annealing conditions. Light illumination at $50 \mu \mathrm{W} \mathrm{cm}$ and $546 \mathrm{~nm}$ was used. The solid lines indicate fits to the data (see text).

We evaluated the OPD performance under various intensities at $\lambda=546 \mathrm{~nm}$ wavelength which lies at the P3HT:PCBM BiHJ absorption peak. The semi-log $J-V$ characteristic at $50 \mu \mathrm{W} \mathrm{cm}{ }^{-2}$ light intensity for devices prepared with different annealing conditions is shown in Figure 4. Photocurrents as a function of

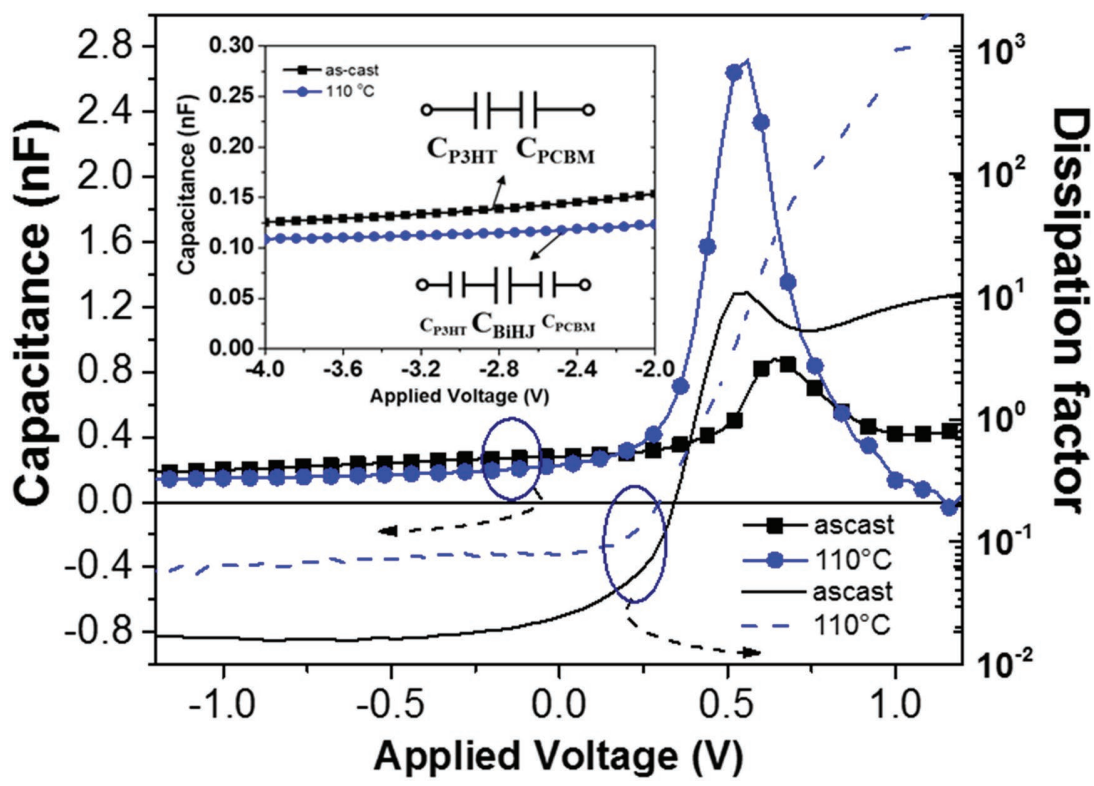

Figure 5. Capacitance-voltage $(\mathrm{C}-\mathrm{V})$ characteristics of the $\mathrm{BiH}) \mathrm{OPDs}$ with as-cast and $110^{\circ} \mathrm{C}$ annealing conditions along with dissipation factor $(D=1 / \omega R C, R$ is device resistance). Inset: $C-V$ characteristics from -2 to $-4 \mathrm{~V}$. Also shown are equivalent capacitance circuits for each device. Negative bias was applied to anode electrode. intensity at $-1.5 \mathrm{~V}$ bias for $110{ }^{\circ} \mathrm{C} \mathrm{BiHJ} \mathrm{OPD}$ are shown in Figure 6a. The figure indicates that the optimized $\mathrm{BiHJ}$ OPD can respond to irradiance levels as low as $\approx 10 \mathrm{nW} \mathrm{cm}^{-2}$ at which point the photoresponse is limited by the dark current.

The linear dynamic range (LDR) is defined as, LDR $=20 \log \left(J^{*}{ }_{\mathrm{ph}} / J_{\mathrm{d}}\right)[\mathrm{dB}]$ where $J^{*}{ }_{\mathrm{ph}}$ is the photocurrent density of the OPD, deviating from linearity by $10 \% .{ }^{[40]}$ Figure $6 \mathrm{~b}$ shows the LDR of the $110{ }^{\circ} \mathrm{C}$ annealed OPD at $-1.5 \mathrm{~V}$ and $\lambda=546 \mathrm{~nm}$ is $>120 \mathrm{~dB}$; the OPD exhibits no apparent photocurrent saturation up to $0.1 \mathrm{~W} \mathrm{~cm}^{-2}$. 1$]$

Figure 7a compares the measured external quantum efficiency (EQE) of the as-cast and $110{ }^{\circ} \mathrm{C}$ annealed OPDs for biases of 0 , $-1.5,-3$, and $-4.5 \mathrm{~V}$. The EQE of the as-cast device is considerably lower than the $110{ }^{\circ} \mathrm{C}$ annealed device across the entire spectral range measured. The unannealed device shows a peak $\mathrm{EQE}=12 \% \pm 2 \%$ at $\lambda=435 \mathrm{~nm}$, while the $110{ }^{\circ} \mathrm{C} \mathrm{BiHJ}$ OPD showed the highest $\mathrm{EQE}=62 \% \pm 2 \%$ at $-4.5 \mathrm{~V}$ at $\lambda=$ $555 \mathrm{~nm}$.

To clarify the difference in peak wavelength locations, the optical field distribution in the device was calculated using the transfer matrix method, ${ }^{[41]}$ with results in Figure $7 \mathrm{~b}$. For the as-cast device, we assumed partially interdiffused $\mathrm{BiHJ}$ network having a $\mathrm{BiHJ}$ layer thickness of $10 \mathrm{~nm}$ sandwiched between $90 \mathrm{~nm}$ thick P3HT and PCBM layers. The BiHJ $110{ }^{\circ} \mathrm{C}$ device is assumed to have a $160 \mathrm{~nm}$ thick interdiffused $\mathrm{BiHJ}$ layer sandwiched between $10 \mathrm{~nm}$ thick P3HT and PCBM layers. For the as-cast device, we calculate a peak photon absorption from 400 to $450 \mathrm{~nm}$ at the interface of the D/A layers, gradually decreasing with increasing wavelength. This is consistent with the experimental EQE obtained for the as-cast device, which implies that absorption within the $\mathrm{BHJ}$ is the primary site for photogeneration. The absorption at $\lambda=400 \mathrm{~nm}$ within the PCBM layer and at $\lambda=600 \mathrm{~nm}$ in the P3HT layer generates excitons that rapidly recombine due to the absence of a D/A junction within a diffusion length of $\approx 5-20 \mathrm{~nm} .{ }^{[42,43]}$ In contrast, $110{ }^{\circ} \mathrm{C}$ annealed device showed broad overlapping regions of photon absorption from $\lambda=500$ to $600 \mathrm{~nm}$, contributing directly to photogeneration of carriers in the extended interdiffused D/A junction.

Finally, to characterize the performance of OPD, we evaluated the OPD figure of merit measured at $\lambda=546 \mathrm{~nm}$ and at an intensity of $50 \mu \mathrm{W} \mathrm{cm}$. The calculated figures of merit (FOMs) of the OPDs $\left(J_{d}\right.$, EQE, responsivity (R), noise equivalent 

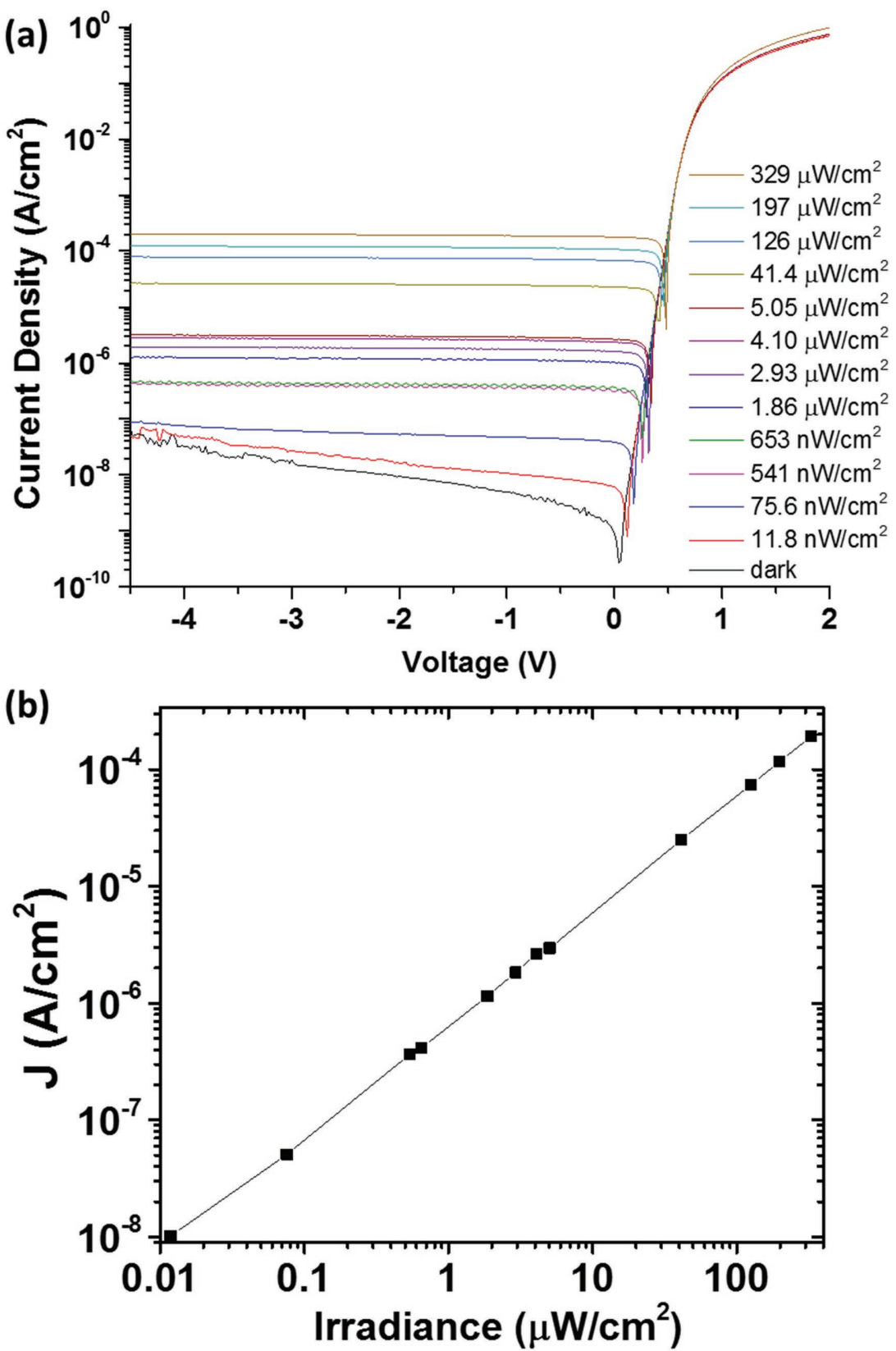

Figure 6. a) $\mathrm{J}-\mathrm{V}$ curve of the $\mathrm{BiHJ} \mathrm{OPD}$ with $110^{\circ} \mathrm{C}$ annealing condition under various light intensities at $546 \mathrm{~nm}$ wavelength. b) Variation of the photocurrent with irradiance of the $\mathrm{BiH}$ ) OPD annealed at $110^{\circ} \mathrm{C}$ under monochromatic light of $546 \mathrm{~nm}$ and reverse bias of $1.5 \mathrm{~V}$. Negative bias was applied to anode electrode.

power (NEP), and specific detectivity $\left(D^{*}\right)$ ) are summarized in Table 2. The definition of each FOMs can be found in the Supporting Information. ${ }^{[40]}$ While the lowest $J_{\mathrm{d}}$ was achieved by annealing at $110{ }^{\circ} \mathrm{C}$, and the highest observed for the $150{ }^{\circ} \mathrm{C}$ device, both devices have $\mathrm{R}=240 \pm 10 \mathrm{~mA} \mathrm{~W}^{-1}$. The comparable $\mathrm{R}$ values confirm that annealing at $110^{\circ} \mathrm{C}$ is suffcient to induce interdiffusion layer, leading to the maximum photoresponse. The $110{ }^{\circ} \mathrm{C}$ device showed $D^{*}=(4.82 \pm 0.2) \times$ $10^{12} \mathrm{~cm} \mathrm{~Hz}^{1 / 2} \mathrm{~W}^{-1}$ due to the lowest dark current of $J_{\mathrm{d}}=(7.72 \pm$ $0.3) \times 10^{-9} \mathrm{~A} \mathrm{~cm}^{-2}$ at $-1.5 \mathrm{~V}$, which is among the best reported values for P3HT:PCBM based heterojunction OPDs. ${ }^{[44-46]}$

We demonstrated a novel DTS printing method of organic photodiodes with controlled donor/acceptor interdiffused heterojunctions sandwiched between donor and acceptor layers. Thermal annealing maximized the D/A interface within a welldefined volume. We demonstrated an OPD with a specific detectivity of $(4.82 \pm 0.2) \times$ $10^{12} \mathrm{~cm} \mathrm{~Hz}^{1 / 2} \mathrm{~W}^{-1}$ at $1.5 \mathrm{~V}$ reverse bias with $J_{\text {dark }}=(7.7 \pm 0.3) \times 10^{-9} \mathrm{~A} \mathrm{~cm}^{-2}$ and $\mathrm{EQE}=$ $60 \% \pm 1 \%$. The DTS method can be applied to a variety of fullerene/polymer heterojunction system. The processing method is expected to allow freedom in selecting solvent systems for numerous materials to achieve a desired active layer morphology within the bulk heterojunction.

\section{Experimental Section}

PDMS Stamp and Solution Preparation: PDMS stamps were prepared by mixing Sylgard 184 silicone elastomer (Dow Corning) and a curing agent in a clean room ( $43 \%$ relative humidity, $20{ }^{\circ} \mathrm{C}$ temperature) environment. ${ }^{[47]}$ Various ratios of Sylgard: curing agent by mass were prepared to yield different surface energies. The two components were mixed for $10 \mathrm{~min}$ and degassed at $\approx 0.4$ psi for $6 \mathrm{~h}$ before being poured onto plastic weighing boats and cured at room temperature for $3 \mathrm{~d}$. The PDMS stamps were peeled off from the boats and then cut into $1.5 \times 1.5 \mathrm{~cm}^{2}$ pieces. The PDMS stamps' thicknesses were $\approx 5 \mathrm{~mm}$. The PDMS stamps were attached to glass wafers for transfer. The PEIE solution was prepared by dissolving $5 \mathrm{wt} \%$ of PEIE (SigmaAldrich) in 2-methoxyethanol (Sigma-Aldrich) solvent in atmosphere. Two active layer solutions were prepared in a $\mathrm{N}_{2}$-filled glove box: (1) $\mathrm{P} 3 \mathrm{HT}$ solution: $14 \mathrm{mg}$ of P3HT (Rieke Metals, $\approx 91 \%$ regioregularity) was dissolved in $1.5 \mathrm{~mL}$ of $\mathrm{CB}$ (Sigma-Aldrich) solvent; and (2) PCBM solution: $25 \mathrm{mg}$ of PCBM (American Dye Source, purity: $>99.5 \%$ ) was dissolved in $1 \mathrm{~mL}$ of CB. All solutions were filtered by $0.45 \mu \mathrm{m}$ syringe filter and then stirred by magnetic bar overnight at $70^{\circ} \mathrm{C}$.

Measurements: Contact angle measurements used a contact angle goniometer (Ramé-Hart) in a clean room (43\% relative humidity, $20^{\circ} \mathrm{C}$ temperature). The static sessile drop method was used to measure the advancing angle of the $\mathrm{P} 3 \mathrm{HT}$ in $\mathrm{CB}$ solution droplet on the PDMS stamps. Optical absorbance spectra of the $\mathrm{BiH}$ ) films were measured using an Agilent CARY-5E UV-vis spectrometer. Dark current density-voltage $(U-V)$ characteristics were measured by HP2416A semiconductor measurement system with a probe station at room temperature in air. For the $J-V$ measurement of the OPDs under illumination, a solar simulator (Oriel) equipped with a Xe lamp, a band pass filter with peak wavelength at $546 \mathrm{~nm}$ (FWHM (full width at half maximum) $=10 \mathrm{~nm}$ ), and a $4156 \mathrm{C}$ semiconductor parameter analyzer was used. The devices were located inside the glove box and illumination was via the glass substrate. A liquid light guide (Newport, 

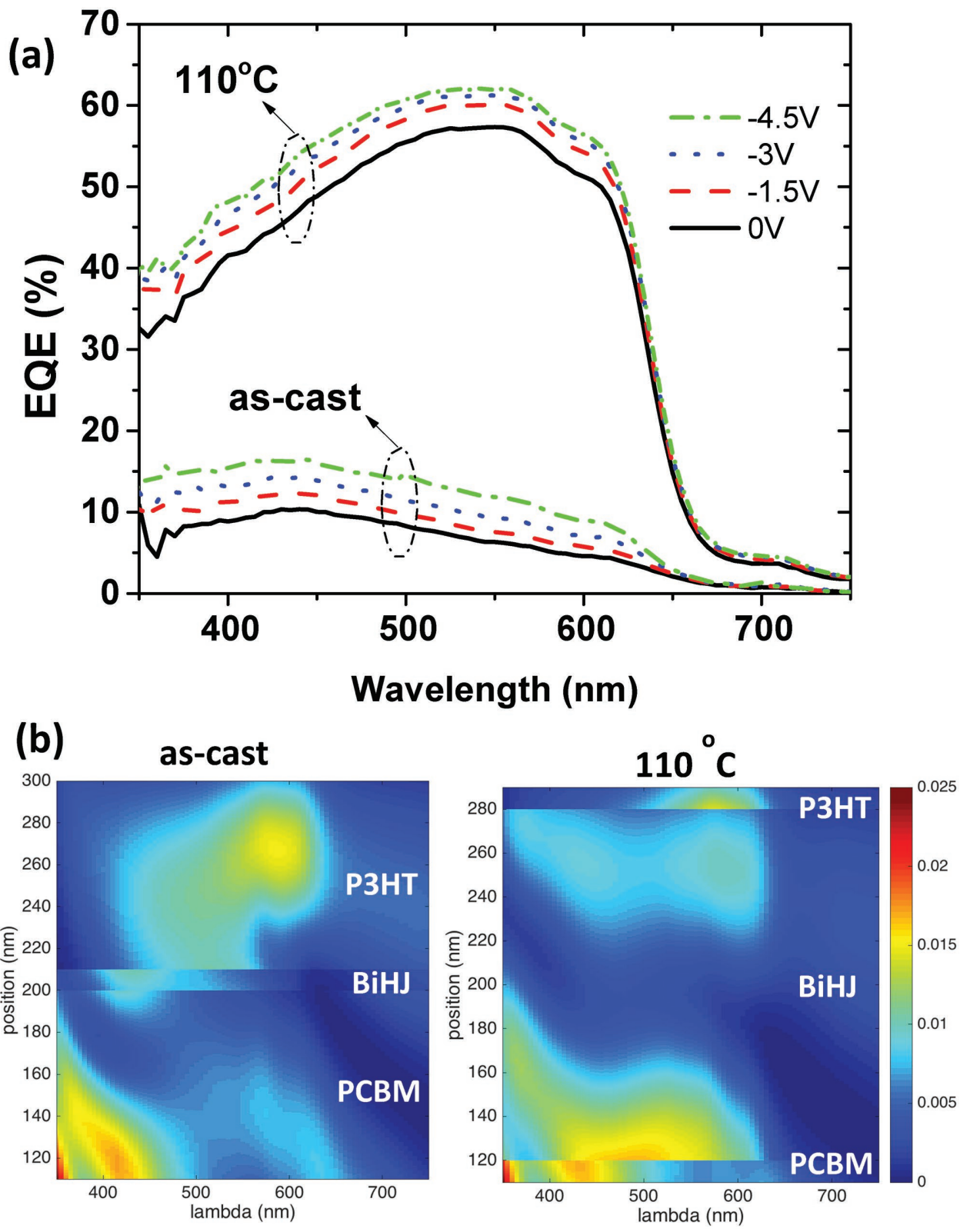

Figure 7. a) External quantum efficiency (EQE) spectrum of the $\mathrm{BiH}$ OPDs under various reverse biases with as-cast and $110^{\circ} \mathrm{C}$ annealing conditions b) Absorbed optical power distribution of the $\mathrm{BiH}$ J OPD active layers with as-cast (left) and $110^{\circ} \mathrm{C}$ (right) annealing conditions. The light is illuminated through the substrate.

$5 \mathrm{~mm}$ diameter) and a broadband mirror were used for illumination. The intensity of the monochromatic light was measured by a radiant power meter (70260, Newport) using the same configuration. External

Table 2. Performance of OPDs with different annealing conditions at irradiance of $50 \mu \mathrm{W} \mathrm{cm}$ at $546 \mathrm{~nm}$ wavelength.

\begin{tabular}{|c|c|c|c|c|}
\hline $\begin{array}{l}\text { Annealing } \\
\text { conditions }\end{array}$ & $\begin{array}{c}\mathrm{R}\left[\mathrm{mA} \mathrm{W} \mathrm{W}^{-1}\right] \\
@-1.5 \mathrm{~V}\end{array}$ & $\begin{array}{l}\text { EQE [\%] } \\
@-1.5 \mathrm{~V}\end{array}$ & $\begin{array}{c}\mathrm{NEP}\left[\mathrm{W} \mathrm{Hz} \mathrm{H}^{-1 / 2}\right] @ \\
-1.5 \mathrm{~V}\end{array}$ & $\begin{array}{c}D *\left[\mathrm{~cm} \mathrm{~Hz} z^{1 / 2} \mathrm{~W}^{-1}\right] \\
@-1.5 \mathrm{~V}\end{array}$ \\
\hline As-cast & 28 & 8 & $5.51 \times 10^{-13}$ & $1.61 \times 10^{11}$ \\
\hline $70^{\circ} \mathrm{C}$ & 75 & 14 & $1.38 \times 10^{-13}$ & $6.44 \times 10^{11}$ \\
\hline $110^{\circ} \mathrm{C}$ & 240 & 60 & $1.84 \times 10^{-14}$ & $4.82 \times 10^{12}$ \\
\hline $150^{\circ} \mathrm{C}$ & 243 & 61 & $2.59 \times 10^{-13}$ & $3.42 \times 10^{11}$ \\
\hline
\end{tabular}

quantum efficiency was measured from 0 to $-4.5 \mathrm{~V}$. Incident light from a tungsten halogen lamp passing through a monochromator was chopped at $200 \mathrm{~Hz}$ to illuminate the device. The generated AC photocurrent was amplified by a current amplifier (KEITHLEY 428) and then detected by a lock-in amplifier (SRS 830, Stanford Research) that also provided reverse bias. A UV-enhanced silicon photodetector (UV808, Newport) was used for the light intensity calibration. Capacitance-voltage $(C-V)$ measurements were performed in air using HP4284A LCR meter at room temperature in the dark. The amplitude of the smallsignal voltage for the $C-V$ measurement was $25 \mathrm{mV}$ with frequency of $1 \mathrm{kHz}$.

Optical Modeling: Optical simulations used the transfer matrix method. ${ }^{[11,48]}$ The complex refractive index $(\boldsymbol{n}=n+i k)$ of each material was acquired by a spectroscopic ellipsometer (M-2000, J. A. Woollam) with a B-spline fitting function (Figure S3, Supporting Information). The 
electric field and absorbed optical power distributions were calculated as done previously. ${ }^{[4]]}$

\section{Supporting Information}

Supporting Information is available from the Wiley Online Library or from the author.

Received: September 26, 2016 Revised: October 27, 2016 Published online: December 27, 2016

[1] X. Gong, M. Tong, Y. Xia, W. Cai, J. S. Moon, Y. Cao, G. Yu, C.-L. Shieh, B. Nilsson, A. J. Heeger, Science 2009, 325, 1665.

[2] X. Zhou, D. Yang, D. Ma, Adv. Opt. Mater. 2015, 3, 1570.

[3] C. H. Cheung, D. Y. Kim, J. Subbiah, C. M. Amb, J. R. Reynolds, F. So, IEEE Trans. Electron Devices 2014, 61, 3852.

[4] P. E. Keivanidis, S.-H. H. Khong, P. K. H. Ho, N. C. Greenham, R. H. Friend, Appl. Phys. Lett. 2009, 94, 173303.

[5] A. Pierre, I. Deckman, P. B. Lechêne, A. C. Arias, Adv. Mater. 2015, 27,6411

[6] F. Guo, B. Yang, Y. Yuan, Z. Xiao, Q. Dong, Y. Bi, J. Huang, Nat. Nanotechnol. 2012, 7, 798.

[7] X. Hu, K. Wang, C. Liu, T. Meng, Y. Dong, S. Liu, F. Huang, X. Gong, Y. Cao, J. Mater. Chem. C 2014, 2, 9592.

[8] P. Peumans, V. Bulovic, S. R. Forrest, Appl. Phys. Lett. 2000, 76, 3855

[9] G. Yu, J. Gao, J. C. J. Hummelen, F. Wudl, A. J. Heeger, Science $1995,270,1789$.

[10] K.-J. Baeg, M. Binda, D. Natali, M. Caironi, Y.-Y. Noh, Adv. Mater. 2013, 25, 4267.

[11] M. Binda, A. lacchetti, D. Natali, L. Beverina, M. Sassi, M. Sampietro, Appl. Phys. Lett. 2011, 98, 073303.

[12] V. S. Gevaerts, L. J. A. Koster, M. M. Wienk, R. A. J. Janssen, ACS Appl. Mater. Interfaces 2011, 3, 3252.

[13] A. L. Ayzner, C. J. Tassone, S. H. Tolbert, B. J. Schwartz, J. Phys. Chem. C 2009, 113, 20050.

[14] B. A. Collins, E. Gann, L. Guignard, X. He, C. R. McNeill, H. Ade, J. Phys. Chem. Lett. 2010, 1, 3160.

[15] K. H. Lee, P. E. Schwenn, A. R. G. Smith, H. Cavaye, P. E. Shaw M. James, K. B. Krueger, I. R. Gentle, P. Meredith, P. L. Burn, Adv. Mater. 2011, 23, 766.

[16] J. S. Moon, C. J. Takacs, Y. Sun, A. J. Heeger, Nano Lett. 2011, 11, 1036.

[17] D. Chen, A. Nakahara, D. Wei, D. Nordlund, T. P. Russell, Nano Lett. 2011, 11, 561.

[18] H. W. Ro, B. Akgun, B. T. O'Connor, M. Hammond, R. J. Kline, C. R. Snyder, S. K. Satija, A. L. Ayzner, M. F. Toney, C. L. Soles, D. M. DeLongchamp, Macromolecules 2012, 45, 6587.

[19] D. Leman, M. A. Kelly, S. Ness, S. Engmann, A. Herzing, C. Snyder, H. W. Ro, R. J. Kline, D. M. DeLongchamp, L. J. Richter, Macromolecules 2015, 48, 383.

[20] B. L. Chen, P. Degenaar, D. D. C. Bradley, Adv. Mater. 2008, 20, 1679.
[21] H. Kim, K.-T. Lee, C. Zhao, L. J. Guo, J. Kanicki, Org. Electron. 2015, 20, 103.

[22] H.-L. Yip, A. K.-Y. Jen, Energy Environ. Sci. 2012, 5, 5994.

[23] F. Arca, S. F. Tedde, M. Sramek, J. Rauh, P. Lugli, O. Hayden, Sci. Rep. 2013, 3, 1324.

[24] S. Dongaonkar, J. D. Servaites, G. M. Ford, S. Loser, J. Moore, R. M. Gelfand, H. Mohseni, H. W. Hillhouse, R. Agrawal, M. A. Ratner, T. J. Marks, M. S. Lundstrom, M. A. Alam, J. Appl. Phys. 2010, 108, 124509.

[25] B. V. Popescu, D. H. Popescu, P. Lugli, S. Locci, F. Arca, S. F. Tedde, M. Sramek, O. Hayden, IEEE Trans. Electron Devices 2013, 60, 1975 .

[26] I. Hwang, D. Moses, A. J. Heeger, J. Phys. Chem. C 2008, 112, 4350.

[27] Y. Zhou, C. Fuentes-Hernandez, J. Shim, J. Meyer, A. J. Giordano, H. Li, P. Winget, T. Papadopoulos, H. Cheun, J. Kim, M. Fenoll, A. Dindar, W. Haske, E. Najafabadi, T. M. Khan, H. Sojoudi, S. Barlow, S. Graham, J.-L. Brédas, S. R. Marder, A. Kahn, B. Kippelen, Science 2012, 336, 327.

[28] J. Meyer, A. Kahn, J. Photonics Energy 2011, 1, 011109.

[29] N. D. Treat, M. A. Brady, G. Smith, M. F. Toney, E. J. Kramer, C. J. Hawker, M. L. Chabinyc, Adv. Energy Mater. 2011, 1, 82.

[30] H. Sirringhaus, P. J. Brown, R. H. Friend, M. M. Nielsen, Nature 1999, 401, 685.

[31] V. Shrotriya, J. Ouyang, R. J. Tseng, G. Li, Y. Yang, Chem. Phys. Lett. 2005, 411, 138 .

[32] R. Kroon, M. Lenes, J. C. Hummelen, P. W. M. Blom, B. de Boer Polym. Rev. 2008, 48, 3.

[33] N. C. Giebink, B. E. Lassiter, G. P. Wiederrecht, M. R. Wasielewski, S. R. Forrest, Phys. Rev. B: Condens. Matter Mater. Phys. 2010, 82, 1.

[34] S. M. Sze, Physics of Semiconductor Devices, Wiley-Interscience, Hoboken, NJ, USA 2007.

[35] R. F. Pierret, Semiconductor Device Fundamentals, Addison-Wesley, Boston, MA, USA 1996.

[36] M. Mingebach, C. Deibel, V. Dyakonov, Phys. Rev. B: Condens. Matter Mater. Phys. 2011, 84, 1.

[37] Y.-S. S. Cho, R. R. Franklin, Trans. Electr. Electron. Mater. 2012, 13, 237.

[38] F. Jahani, S. Torabi, R. C. Chiechi, L. Jan, A. Koster, J. C. Hummelen, Chem. Commun. 2014, 50, 10645.

[39] C. Wohlfarth, Dielectric constant of chlorobenzene. Supplement to IV/6. Springer, Berlin, Germany 2008, pp. 323-325.

[40] J.-M. Liu, Photonic Devices, Cambridge University Press, Cambridge, UK 2005

[41] L. A. A. Pettersson, L. S. Roman, O. Inganäs, J. Appl. Phys. 1999, 86, 487.

[42] P. E. Shaw, A. Ruseckas, I. D. W. Samuel, Adv. Mater. 2008, 20, 3516.

[43] G. F. Burkhard, E. T. Hoke, S. R. Scully, M. D. McGehee, Nano Lett. 2009, 9, 4037.

[44] M. Ramuz, L. Bürgi, C. Winnewisser, P. Seitz, Org. Electron. 2008, 9 , 369.

[45] D. Baierl, B. Fabel, P. Gabos, L. Pancheri, P. Lugli, G. Scarpa, Org. Electron. 2010, 11, 1199.

[46] S. F. Tedde, J. Kern, T. Sterzl, J. Fu, P. Lugli, O. Hayden, Nano Lett. 2009, 9, 980

[47] Y. Xia, G. M. Whitesides, Annu. Rev. Mater. Sci. 1998, 28, 153.

[48] P. Peumans, A. Yakimov, S. R. Forrest, J. Appl. Phys. 2003, 93, 3693. 